\title{
UMA ABORDAGEM FORMALISTA PARA A REGULAÇÃO POR AGÊNCIAS
}

\section{Lucas dos Reis Montenegro*}

Resumo: O formalismo jurídico é alvo de uma série de caricaturas e adjetivações. É tido como vetusto e superado. A Regulação, por sua vez, surge dentro de uma linha de modernização do Direito Público. Haveria, contudo, um espaço de conciliação entre o Formalismo e a Regulação? O artigo defende que sim, especialmente em relação à Regulação por Agências. $O$ formalismo enquanto técnica interpretativa seria útil para delimitar adequadamente a esfera de atuação das Agências, evitando tanto uma espécie de excesso de controle judicial quanto um expansionismo da própria Agência.

Palavras-chave: Formalismo Jurídico. Teoria da Regulação. Competências. Deferência.

\section{A FORMALIST APPROACH TO REGULATION BY AGENCIES}

Abstract: Legal formalism is a target for a series of mockeries and adjectivities. It is treated as past and archaic. Regulation, on the other hand, shows itself under a trend of modernizing Public Law. Would it be a conciliatory space to be shared by Legal Formalism and Regulation? This article defends that it does, specially in regard of Regulation by Agencies. Formalism as an interpretation tool would be useful to draw the Agency's turf of operation, avoiding both an excess of judicial control and an expansionist view by the Agency itself.

Keywords: Legal Formalism. Theory of Regulation. Competences. Deference.

\section{Introdução}

Não seria um exagero afirmar a existência de uma tendência, dentre estudiosos do Direito, em associar rótulos e erigir espantalhos como forma de desqualificar correntes do pensamento jurídico com as quais não se concorde. $\mathrm{O}$ formalismo jurídico é uma das vítimas de predileção.

Caracterizado por vezes como démodé, autoritário e tosco, o formalismo, ainda assim, não apenas sobrevive como mantém sua relevância dentro da Academia.

Se de um lado temos o "ultrapassado" formalismo, do outro temos o estudo da Regulação, tão associado, a seu turno, a termos avant-garde (e um tanto anglófonos) do Direito, como cost-benefit analysis; accountability; market failures; law and economics etc.

Mestrando em Direito da Regulação pela FGV/Direito Rio; pós-graduado em Direito Administrativo pela Universidade Cândido Mendes; bacharel em Direito pela UFRJ. Advogado. Email: lucas.montenegro@fgv.edu.br 
Teria esse moderno (ou pós-moderno) ramo do Direito algo a extrair do "vetusto" formalismo jurídico? Este artigo é fruto, justamente, desta inquietação.

A Regulação, especificamente a Regulação por Agências, tem em seu núcleo a ideia de mandatos legislativos conferidos pelo Parlamento a entidades da Administração, para que estas atuem como reguladoras de determinado setor. A interpretação do alcance de tais mandatos é, portanto, central a este modelo regulatório.

Não à toa o seminal caso norte-americano Chevron U.S.A., Inc. v. Natural Resources Defense Council, Inc. trata, especificamente, de interpretação de mandatos legislativos. Chevron pode ser compreendido, conforme será trabalhado ao longo do artigo, a partir de uma chave de leitura formalista, por exemplo.

A ideia a ser desenvolvida é no sentido de que o formalismo jurídico é subjacente à Regulação por Agências, possuindo, dentro desse modelo, uma dúplice função: (i) fomentar a deferência judicial à regulação; e (ii) atuar como mecanismo interno de autocontenção daquilo que pode ser chamado de uma tendência interna da Agência em extrapolar o mandato que lhe foi conferido pela Lei.

$\mathrm{O}$ artigo pretende se desenvolver da seguinte forma: (i) a primeira seção tratará das caracterizações feitas em relação ao formalismo, partir de uma ideia de "formalismo enquanto adjetivo" e trará conceitos de formalismo a partir de adeptos dessa teoria jurídica, tentando apresentar o formalismo em sua melhor acepção, para, logo após, estabelecer o que se entenderá, para fins deste trabalho, por formalismo jurídico; (ii) a segunda seção cuidará de esmiuçar aquilo que o formalismo jurídico pode oferecer enquanto teoria interpretativa; (iii) a terceira seção, já adentrando a Teoria da Regulação, traçará breves comentários acerca do modelo de Regulação por Agências e analisará o modelo de delegação de poderes feito às Agências pelo Legislativo, tomando por base as leis criadoras das Agências brasileiras e o seminal caso Chevron; (iv) a quarta seção desenvolverá a ideia central do trabalho, relacionando o formalismo jurídico e dois possíveis dilemas enfrentados pelas Agências: controle por parte do Judiciário e uma tendência expansiva da própria Agência; (v) a quinta seção, por fim, recapitulará alguns dos temas trabalhados para, após, concluir.

A metodologia adotada será a revisão de literatura. O artigo, apesar de descritivo na medida em que descreve a Regulação por Agências através de uma leitura do formalismo jurídico, não se furtará de um certo tom normativo, pois prescreverá o formalismo como uma 
alternativa teórica interessante para a solução de certos impasses afetos à Regulação por Agência.

\title{
FORMALISMO PARA ALÉM DAS CARICATURAS
}

O formalismo jurídico é tratado, por vezes, de uma forma caricatural. A palavra formalista serve como um adjetivo para descrever qualquer decisão judicial ou pensamento jurídico com os quais não se concorde (SCHAUER, 1988, p. 510), inclusive de uma forma execratória e pejorativa (LEAL, 2014, p. 247).

Para fins da caracterização do formalismo enquanto adjetivo, Leal (2018, p. 102) descreve diferentes sentidos:

\begin{abstract}
No primeiro desses sentidos, formalismo costuma se referir à compreensão da decisão jurídica (notadamente da decisão judicial) como produto de uma proposição factual a uma proposição normativa, ambos de significado claro. Ser formalista, com outras palavras, significa acreditar e defender que juízes, quando decidem, extraem sempre conclusões cuja força decorre de um raciocínio lógico-dedutivo: dados os fatos e conhecido o Direito, segue-se a solução jurídica para o problema a partir de um tipo de "encaixe" entre aquilo que o direito prevê por meio de seus padrões gerais e o evento particular constatado no mundo. Por trás dessa visão, está a crença de que o formalismo se assenta sobre uma completa autonomia do Direito em relação à política. No segundo sentido, ser formalista significa acreditar que o conjunto normativo que compõe o Direito de uma determinada comunidade política pode ser organizado em um sistema dotado das seguintes propriedades: dele é capaz de se extrair respostas para todos os problemas jurídicos, não sendo necessário recorrer a elementos extrajurídicos para solucioná-los (o sistema é, portanto, fechado), ele não contém lacunas (sendo, assim, completo), não compreende antinomias (ele é consistente) e as suas normas são de sentido imediatamente apreensível, não havendo vagueza nem ambiguidades nas formulações linguísticas que as comunicam (o sistema é claro).
\end{abstract}

O formalista seria, assim, aquele que crê que a atividade decisória se desenvolve através de uma forma quase automática, mecânica, por meio da qual se identifica um problema a ser resolvido, se aplica o direito subjacente e se chega a uma decisão ${ }^{1}$, decisão que seria certa e não careceria de elementos extrajurídicos, pois o sistema do direito seria completo e suficientemente claro.

O formalista seria, ainda, aquele decisor que aplica a regra relativa ao caso, sem dela se desviar, ainda que a sua aplicação gere injustiça (STOKES, 1994, p. 133).

1 Brian Leiter denomina essa visão acerca do formalismo jurídico como sendo o Formalismo Vulgar (Vulgar Formalism): "I also note that formalism is sometimes associated with the idea that judicial decision-making involves nothing more than mechanical deduction on the model of syllogism [...]. I call the latter Vulgar 
Essa leitura caricatural do formalismo jurídico já foi feita, inclusive, no âmbito do Supremo Tribunal Federal, ocasião na qual se afirmou que o formalismo seria legicentrista e oposto a uma visão "neoconstitucional do Direito".2

Formalism to emphasize that is not a view to which anyone today cares to subscribe." (LEITER, 2010, p. 111).

2 "Ementa: EMBARGOS DE DECLARAÇÃO. RECURSO INTERPOSTO ANTES DA PUBLICAÇÃO DO ACÓRDÃO. CONHECIMENTO. INSTRUMMENTALISMO PROCESSUAL. PRECLUSÃO QUEE NÃO PODE PREJUDICAR A PARTE QUE CONTRIBUI PARA A CELERIDADE DO PROCESSO. BOA-FÉ EXIGIDA DO ESTADO-JUIZ. DOUTRINA. RECENTE JURISPRUDÊNCIA DO PLENÁRIO. MÉRITO. ALEGAÇÃO DE OMISSÃO E CONTRADIÇÃO. INEXISTÊNCIA. RECURSO CONHECIDO E REJEITADO. 1. A doutrina moderna ressalta o advento da fase instrumentalista do Direito Processual, ante a necessidade de interpretar os seus institutos sempre do modo mais favorável ao acesso à justiça (art. 5. ${ }^{\circ}$, $\mathrm{XXXV}, \mathrm{CRFB}$ ) e à efetividade dos direitos materiais (OLIVEIRA, Carlos Alberto Alvaro de. O formalismovalorativo no confronto com o formalismo excessivo. In: Revista de Processo, São Paulo: RT, n. ${ }^{\circ}$ 137, p. 731, 2006; DINAMARCO, Cândido Rangel. A instrumentalidade do processo. $14^{a}$ ed. São Paulo: Malheiros, 2009; BEDAQUE, José Roberto dos Santos. Efetividade do Processo e Técnica Processual. $3^{\text {a }}$ ed. São Paulo: Malheiros, 2010). 2. "A forma, se imposta rigidamente, sem dúvidas conduz ao perigo do arbítrio das leis, nos moldes do velho brocardo dura lex, sed lex" (BODART, Bruno Vinícius Da Rós. Simplificação e adaptabilidade no anteprojeto do novo CPC brasileiro. In: O Novo Processo Civil Brasileiro - Direito em Expectativa. Org. Luiz Fux. Rio de Janeiro: Forense, 2011. p. 76). 3. As preclusões se destinam a permitir o regular e célere desenvolvimento do feito, por isso que não é possível penalizar a parte que age de boa-fé e contribui para o progresso da marcha processual com o não conhecimento do recurso, arriscando conferir o direito à parte que não faz jus em razão de um purismo formal injustificado. 4. O formalismo desmesurado ignora a boa-fé processual que se exige de todos os sujeitos do processo, inclusive, e com maior razão, do Estado-Juiz, bem como se afasta da visão neoconstitucionalista do direito, cuja teoria proscreve o legicentrismo e o formalismo interpretativo na análise do sistema jurídico, desenvolvendo mecanismos para a efetividade dos princípios constitucionais que abarcam os valores mais caros à nossa sociedade (COMANDUCCI, Paolo. Formas de (neo)constitucionalismo: un análisis metateórico. Trad. Miguel Carbonell. In: "Isonomía. Revista de Teoría y Filosofía del Derecho", n. $\left.{ }^{\circ} 16,2002\right)$. 5. O Supremo Tribunal Federal, recentemente, sob o influxo do instrumentalismo, modificou a sua jurisprudência para permitir a comprovação posterior de tempestividade do Recurso Extraordinário, quando reconhecida a sua extemporaneidade em virtude de feriados locais ou de suspensão de expediente forense no Tribunal a quo (RE 626.358-AgR/MG, rel. Min. Cezar Peluso, Tribunal Pleno, julg. 22/03/2012). 6. In casu: (i) os embargos de declaração foram opostos, mediante fac-símile, em 13/06/2011, sendo que o acórdão recorrido somente veio a ser publicado em 01/07/2011; (ii) o paciente foi denunciado pela suposta prática do crime do art. 12 da Lei . $^{\circ} 6.368 / 79$, em razão do alegado comércio de $2.110 \mathrm{~g}$ (dois mil cento e dez gramas) de cocaína; (iii) no acórdão embargado, a Turma reconheceu a legalidade do decreto prisional expedido pelo Tribunal de Justiça do Estado do Maranhão em face do paciente, para assegurar a aplicação da lei penal, em razão de se tratar de réu evadido do distrito da culpa, e para garantia da ordem pública; (iv) alega o embargante que houve omissão, porquanto não teria sido analisado o excesso de prazo para a instrução processual, assim como contradição, por não ter sido considerado que à época dos fatos não estavam em vigor a Lei n. ${ }^{\circ} 11.343 / 06$ e a Lei . $^{\circ} 11.464 / 07.7$. O recurso merece conhecimento, na medida em que a parte, diligente, opôs os embargos de declaração mesmo antes da publicação do acórdão, contribuindo para a celeridade processual. 8. No mérito, os embargos devem ser rejeitados, pois o excesso de prazo não foi alegado na exordial nem apreciado pelo Superior Tribunal de Justiça, além do que a Lei n. ${ }^{\circ} 11.343 / 06$ e a Lei n. ${ }^{\circ} 11.464 / 07$ em nada interferem no julgamento, visto que a prisão foi decretada com base nos requisitos do art. 312 do CPP identificados concretamente, e não com base na vedação abstrata à liberdade provisória, prevista no art. 44 da Lei de Drogas de 2006. 9. Embargos de declaração conhecidos e rejeitados." (BRASIL. Supremo Tribunal Federal. HC 101132 ED. Relator: Min. Luiz Fux. Julgamento: 24/04/2012. Órgão Julgador: 1. ${ }^{a}$ Turma. Publicação: ACÓRDÃO ELETRÔNICO DJe-099 DIVULG 21/05/2012 PUBLIC 22/05/2012, grifo nosso). 
Tais visões acerca do formalismo jurídico não podem ser tomadas como definitivas. ${ }^{3}$ É preciso compreender o formalismo nos termos em que é tratado pelos seus defensores, por uma questão de honestidade intelectual. ${ }^{4}$

Larry Alexander define o formalismo jurídico como a aderência à prescrição de uma norma sem levar em conta motivos que estão por detrás dela. $\mathrm{O}$ formalista procura a forma da prescrição e não os fins almejados (ALEXANDER, 2005, p. 2). Alerta, contudo, que a incompatibilidade entre a prescrição e os fins seria uma outra questão a ser resolvida.

Haveria, portanto, uma cisão entre a compreensão da prescrição da norma, ligada a elementos textuais, e a compreensão daquilo que seriam os fins da norma, suas razões de fundo - background reasons, nos termos do autor (ALEXANDER, 2005, p. 2).

O formalismo jurídico é fortemente associado por seus adeptos ao rule of law ${ }^{5}$ : reconhecer o valor do texto da norma em detrimento de suposições acerca dos fins por ela almejados tem aptidão para limitar eventuais exercícios de nomogênese por parte do Poder Judiciário que, ao decidir, teria sua atuação limitada pelo texto de determinada lei ou norma ideia de "government of laws and not of men". 6

Se o formalismo caricatural é associado a uma ideia de adesão ao texto de forma mecânica, sem qualquer preocupação com os fins almejados pela norma, o formalismo nãocaricatural há de ser compreendido como uma inclinação do intérprete a aderir ao texto da norma, ao conteúdo do comando normativo, em detrimento de buscar, ex ante, o fim buscado por tal norma. O formalismo seria, assim, mais uma predisposição do que uma vinculação.

3 É de se notar que a falta de uma definição canônica acerca do que é formalismo jurídico assombra os diferentes autores que procuram trabalhar o tema. Nesse sentido, Posner tenta definir o formalismo jurídico para além daquilo que enxergava como um formalismo do séc. XIX, mas cai na tentação de associá-lo, igualmente, a uma aplicação silogística do direito. (POSNER, 1986, p. 180).

4 A preocupação em tomar uma teoria em sua melhor forma possível é exemplificada por Coleman quando trata do debate positivismo v. jusnaturalismo, debate esse também tão afeto a caricaturas: "our immediate ambition should be to see if we might formulate the natural lawyer's claim charibaly so that it might be the source of insight rather than ridicule." (COLEMAN, 2011, p. 7).

5 Matczak trabalha essa correlação, ainda que de forma a, posteriormente, lançar um desafio ao argumento de que o formalismo seria viabilizador do rule of law. (MATCZAK, 2018, p. 65).

6 A Separação dos Poderes com a determinação de espaços específicos de atuação foi trabalhada pela Constituição de Massaschusetts de 1780, que em seu artigo 30 determina que: "In the government of this commonwealth, the legislative department shall never exercise the executive and judicial powers, or either of them: the executive shall never exercise the legislative and judicial powers, or either of them: the judicial shall never exercise the legislative and executive powers, or either of them: to the end it may be a government of laws and not of men." (Constituição do Estado de Massaschusetts de 1780). 
Encarar o formalismo jurídico como uma predisposição faz com que não se caia em exemplificações anedóticas como aquela do "proibido veículos" de Hart. ${ }^{7}$

Essa inclinação ao sentido do texto torna o formalismo muito mais atrativo e defensável, justificável, inclusive, à luz de teorias como o pragmatismo jurídico (ARGUELHES; LEAL, 2009).

Interessa, então, analisar aquilo que seriam as vantagens do formalismo, ou, em uma perspectiva consequencialista, as possíveis consequências positivas oferecidas por tal pensamento.

\section{As vantagens do formalismo jurídico}

O direito brasileiro - sobretudo o direito público - passa, hoje, por um quadro de preocupação com consequências práticas de decisões. ${ }^{8}$ Essa preocupação acarretou, inclusive, alterações no texto da Lei de Introdução de Normas do Direito Brasileiro - LINDB, que passou a tratar, em seu art. 20, das "consequências práticas da decisão". 9

Dentro dessa ótica de preocupação com consequências e questões de ordem prática, convém examinar aquilo que se pode denominar como sendo vantagens do formalismo jurídico. Tais vantagens podem ser divididas em teóricas e práticas.

Por vantagens teóricas, cite-se Alexander, que defende que o Direito deve ser formalista por três razões: desacordo; incerteza; e resolução autoritativa (nos termos do autor: disagreement; uncertainty; e authoritative settlement) (ALEXANDER, 2005, p. 5).

O desacordo acerca da aplicação de princípios morais abstratos é inerente à vida de determinada comunidade, bem como a incerteza em relação ao que seria a solução para esse desacordo, seriam resolvidos por uma resolução autoritativa. O formalismo seria apto a oferecer uma resolução autoritativa digna de solucionar tais dilemas.

O formalismo enquanto técnica interpretativa judicial está relacionado à segurança jurídica e à isonomia, pois oferece, nos termos de Schauer, previsibilidade e certeza. O mesmo autor afirma, de modo interessante, que o formalismo seria, em verdade, muito mais

7 A hipotética proibição de veículos em um parque poderia levar um formalista a proibir o uso de bicicletas no mesmo. (HART, H. L. A. apud SCHAUER, 1988, p. 514).

8 Em relação ao direito administrativo, Gustavo Binenbojm classifica essa tendência como sendo o "Giro Pragmático" da disciplina. (BINENBOJM, 2016, p. 52). 
sobre alocação de poder (SCHAUER, 1988, p. 543). Relaciona-se, portanto, com o rule of law e separação dos poderes.

Em termos mais práticos, Cass Sunstein (1999, p. 641) afirma que uma boa defesa do formalismo jurídico deveria ser empírica, buscando responder a seguinte pergunta: "qual seria a estratégia interpretativa que diminui os custos de decisão e de erros?”, especialmente através dos seguintes vetores: (i) se um judiciário mais formalista ou menos formalista produziria mais erros e injustiças; (ii) se os legisladores poderiam antecipar possíveis erros ou injustiças antecipadamente, e se poderiam corrigi-los, se houver, a um custo razoável; e (iii) se um judiciário não-formalista aumentaria significativamente os custos de decisão, sobretudo naquilo que diz respeito à imprevisibilidade.

O formalismo jurídico não, há, portanto, de ser desprezado enquanto teoria como se fosse algo superado e injustificável à luz de visões mais “modernas" sobre o Direito. Ter isso em mente será de grande valia quando adentrarmos os pontos referentes à Teoria da Regulação, o que será feito a seguir.

\section{Teoria da Regulação e Formalismo Jurídico}

Nos Estados Unidos da América, país ao qual podemos atribuir a qualidade de pais do modelo de Regulação por Agências (GUERRA, 2015), há uma certa dificuldade em relação à compreensão do termo Regulação, que se desenvolve de uma maneira um tanto quanto polissêmica. Barach Orbach reconhece que, a despeito dos recursos e tempo investidos em discussões acadêmicas acerca da Regulação, o termo não possui, ainda, uma definição clara, sendo por muitas vezes mal compreendido. ${ }^{10}$

Phillip Selznick reconhece, também, a amplitude conceitual de regulação, afirmando haver uma forte tentação (ao menos na realidade norte-americana, sobre a qual escreveu) em identificar o fenômeno da regulação com todo o reino da lei, ordenação e controle social.

Afirma que isso é compreensível, em razão de a palavra "regulação", tomada por si, ser naturalmente polissêmica, mas afirma que, dentro do contexto de políticas públicas e

9 “Art. 20. Nas esferas administrativa, controladora e judicial, não se decidirá com base em valores jurídicos abstratos sem que sejam consideradas as consequências práticas da decisão".

10 "During the past century, substantial resources have been invested in the politics and scholarship of regulation. Nonetheless, the term "regulation" appears to escape a clear definition. Although regulation has 
administração pública, regulação há de ter um sentido específico, qual seja: "regulation refers to sustained and focusesd control exercised by a public agency over activities that are valued by a community" (SELZNICK, 1985, p. 1).

Por se tratar de uma intervenção em setores da economia, a Regulação contempla elementos de mensuração de suas consequências práticas. É o caso, por exemplo, de técnicas como a Cost-Benefit Analysis - CBA e Análise de Impacto Regulatório (BALDWIN; CAVE; LODGE, 2012, p. 315). ${ }^{11}$ Esses cuidados dão um ar de modernismo à Regulação, tão diferente de figuras arcaicas do Direito (sobretudo do Direito Público) como o Poder de Polícia. ${ }^{12}$

Utilizaremos, para fins deste artigo, Regulação como Regulação por Agências, pois será este modelo regulatório que nos interessa.

A Regulação por Agências tem por característica definidora a criação de entes administrativos dotados de certa independência em relação ao Executivo Central, com capacidades normativas e adjudicatórias conferidas por meio de Lei, que confere a tais Agências uma espécie de mandato.

As Agências devem respeitar o mandato que lhes foi conferido pelo legislador, gozando, porém, de discricionariedade técnica para atuar, dentro dos termos do mandato, sobre o setor regulado.

Interessa ter em mente que as Agências Reguladoras derivam seus poderes de disposições legais. A interpretação do teor de tais mandatos legislativos ganha, portanto, relevância no estudo das Agências Reguladoras, pois determinará o escopo do espaço de atuação das Agências.

O seminal caso norte-americano Chevron U.S.A., Inc. v. Natural Resources Defense Council, Inc cuida, justamente, deste ponto: a controvérsia diz respeito à interpretação da Agência acerca de termos contidos na norma legislativa que lhe delega atribuições. A Suprema Corte norte-americana entendeu que deveria ser dada deferência à interpretação da Agência a partir do seguinte teste: (i) analisar se o Congresso se manifestou diretamente sobre o assunto em questão. Se houver mandamento claro por parte da lei e a decisão da agência

been one of the most controversial topics in law and politics, it has also been one of the most misunderstood concepts in modern legal thinking." (ORBACH, 2012, p. 2.)

11 Para preocupações em relação ao que se pode chamar de um esvaziamento da Análise de Impacto Regulatório, ver: LEAL, 2019.

12 Há autores como Sundfeld que clamam pela superação desta nomenclatura, o que denota uma certa preocupação de modernização do Direito Público, na qual está inserida a Regulação. Nesse sentido: SUNDFELD, 2003. 
contrariá-la, a Corte deverá derrubar a decisão da agência. De outro giro, se a intenção do legislador não resta clara, ou se esse, por meio de parâmetros mínimos, deixou espaço para atuação regulamentar através da agência, passa-se ao passo n. ${ }^{\circ}$ 2; (ii) Se a Corte, no passo 1, entender que a norma do Congresso é ambígua por não ter enfrentado o assunto em questão diretamente, será considerada delegação implícita de poderes à agência, desde que a decisão desta se mostre suficientemente racional, hipótese em que lhe será dada deferência. ${ }^{13}$

A deferência em Chevron é relacionada à compreensão do sentido de uma norma de delegação de competências. A primeira etapa do chamado teste Chevron gira em torno de possíveis divergências entre a interpretação da Agência e sentidos claros extraídos do texto do mandamento legal.

Esta preocupação de Chevron com o sentido claro do texto nos permite afirmar que tal precedente é pautado por uma chave de leitura formalista. Esse possível formalismo em Chevron diz respeito, inclusive, a uma preocupação com alocação de poderes, o que remete à já citada visão de Shauer (1988, p. 543).

Um dos principais casos da Teoria da Regulação, portanto, pode ser considerado um exemplo de aplicação do formalismo jurídico.

Em relação ao Brasil, merecem comentários as leis criadoras das Agências Reguladoras pátrias, de modo a verificar como é trabalhada a questão da delegação de competências ao Regulador.

O art. 2. ${ }^{\circ}$ da Lei n. ${ }^{\circ}$ 13.848/2019 traz o rol atual das Agências Reguladoras federais (atualmente, onze): Aneel; ANP; Anatel; Anvisa; ANS; ANA; Antaq; ANTT; Ancine; Anac; e ANM.

A maioria das leis criadoras das citadas agências, ao conferir-lhes poderes, o faz a partir de um rol de atribuições elencado pelo texto legal. ${ }^{14}$ Delimitar as competências das

13 Suprema Corte dos Estados Unidos da América: 467 U.S. 837, Chevron U.S.A inc. v. Natural Resources Defense Council, inc.

14 Exemplo das leis criadoras da Anatel; Aneel; Ancine; Anac; ANTT e Antaq, que conferem poderes da seguinte forma:

Anatel (Lei n. ${ }^{\circ}$ 9.472/1997)

Art. 19. À Agência compete adotar as medidas necessárias para o atendimento do interesse público e para o desenvolvimento das telecomunicações brasileiras, atuando com independência, imparcialidade, legalidade, impessoalidade e publicidade, e especialmente:

$[\ldots]$

Aneel (Lei n. ${ }^{\circ}$ 9.427/96)

Art. 3. ${ }^{\circ}$ Além das atribuições previstas nos incisos II, III, V, VI, VII, X, XI e XII do art. 29 e no art. 30 da Lei n. ${ }^{\circ} 8.987$, de 13 de fevereiro de 1995 , de outras incumbências expressamente previstas em lei e observado o 
Agências federais se dá, assim, através da interpretação dos comandos normativos que lhes delega tais competências.

A adequada fixação do quantum de poder da Agência carece de uma interpretação que dê prevalência à prescrição normativa, que dê prevalência ao sentido do texto da norma, e não às razões que levaram à criação da Agência ou que determinaram a opção legislativa de regular determinado setor da economia.

A interpretação das normas de delegação de competência às Agências deve, portanto, ser uma interpretação de matiz formalista.

A Regulação é uma área do Direito muito afeta a aproximações com outros setores do conhecimento, como é o caso da Economia, p.e. Adotar o formalismo enquanto técnica interpretativa das leis que conferem poderes às Agências pode ser justificável, ainda, à luz de questões econômicas, como redução de custos de decisão e custos de aconselhamento para as partes atuantes no setor regulado.

Se a aproximação com a Economia clama por abordagens menos teóricas, e tendo em vista que a utilização do formalismo jurídico pode ser justificada sob termos pragmáticos (ARGUELHES; LEAL, 2009), nada impede que haja um jurista pragmaticamente formalista (REDISH; CISAR, 1991, p. 449).

\section{Formalismo e Agências: dois resultados possíveis}

A interpretação formalista que se defende diz respeito a uma tendência do intérprete de seguir o sentido do texto. Dentro da realidade da Regulação por Agências, dar primazia à prescrição do texto legal nos levará a dois cenários, igualmente desejáveis.

A Regulação por Agências lida com normas definidoras de competências, normas que delegam poderes a entidades da Administração. O arranjo institucional das Agências é

disposto no $§ 1 .^{\circ}$, compete à ANEEL: (Redação dada pela Lei n. ${ }^{\circ}$ 10.848, de 2004) (Vide Decreto n. ${ }^{0} 6.802$, de 2009).

[...]

Ancine (MP 2228-1)

Art. 7. ${ }^{\circ}$ A ANCINE terá as seguintes competências:

$[\ldots]$

Anac (Lei n. $\left.{ }^{\circ} 11.182 / 2005\right)$

Art. 3. ${ }^{\circ}$ A Anac, no exercício de suas competências, deverá observar e implementar as orientações, diretrizes e políticas estabelecidas pelo governo federal, especialmente no que se refere a: (Redação dada pela Lei n. ${ }^{\circ}$ 12.462, de 2011)

$[\ldots]$

Teorias do Direito e Realismo Jurídico | e-ISSN: 2525-9601| Encontro Virtual | v. 7 | n. 1 |

p. $43-58$ | Jan/Jul. 2021. 
sujeito a dois possíveis dilemas: um primeiro dilema diz respeito a uma atuação não-deferente do Poder Judiciário.

Se o Judiciário exerce controle excessivo sobre as Agências Reguladoras, a opção legislativa de criação de entidades insularizadas dotadas de expertise técnica para regular determinados setores da economia perde força. Ora, se juízes não especialistas e não eleitos atuam como se reguladores fossem, o modelo de Regulação por Agências perde o sentido.

O Supremo Tribunal Federal, inclusive, não é estranho a leituras que podemos denominar formalistas das leis das Agências. ${ }^{15}$

Um segundo cenário diz respeito a uma possível atuação maximizada por parte da Agência, atuação esta que se valha de interpretações expandidas dos mandatos legislativos que lhes confira competência. ${ }^{16}$

O formalismo jurídico se mostra uma alternativa interpretativa interessante para solucionar ambos os dilemas propostos.

Em relação ao primeiro dilema, o formalismo atua de forma a garantir uma deferência judicial à Agência. Interpretações judiciais limitadas ao conteúdo da norma em detrimento aos motivos que ensejaram a criação da norma restringem o espaço de controle do Judiciário sobre a atuação da Agência. O formalismo jurídico forneceria à Agência uma espécie de núcleo mínimo de atribuições, lastreado no sentido usual dos termos empregados pelo mandato legislativo.

15 “AÇÃO DIRETA DE INCONSTITUCIONALIDADE. PEDIDO DE INTERPRETAÇÃO CONFORME A CONSTITUIÇÃO. ART. 7. ${ }^{\circ}$, III E XV, IN FINE, DA LEI N. ${ }^{\circ}$ 9.782/1999. RESOLUÇÃO DA DIRETORIA COLEGIADA (RDC) DA ANVISA N. ${ }^{\circ}$ 14/2002. PROIBIÇÃO DA IMPORTAÇÃO E DA COMERCIALIZAÇÃO DE PRODUTOS FUMÍGENOS DERIVADOS DO TABACO CONTENDO ADITIVOS. AGÊNCIA NACIONAL DE VIGILÂNCIA SANITÁRIA. REGULAÇÃO SETORIAL. FUNÇÃO NORMATIVA DAS AGÊNCIA REGULADORAS. PRINCÍPIO DA LEGALIDADE. CLÁUSULAS CONSTITUCIONAIS DA LIBERDADE DE INICIATIVA E DO DIREITO À SAÚDE. PRODUTOS QUE ENVOLVEM RISCO À SAÚDE. COMPETÊNCIA ESPECÍFICA E QUALIFICADA DA ANVISA. ART. $8 .^{\circ}, \S 1 .^{\circ}$, X, DA Lei n. ${ }^{\circ}$ 9.782/1999. JURISDIÇÃO CONSTITUCIONAL. DEFERENCIA ADMINISTRATIVA. RAZOABILIDADE. CONVENÇÃO-QUADRO SOBRE CONTROLE DO USO DO TABACO - CQCT. IMPROCEDÊNCIA.

[...]

4. Improcedência do pedido de interpretação conforme a Constituição do art. $7 .^{\circ}, \mathrm{XV}$, parte final, da Lei n. ${ }^{\circ}$ 9.782/1999, cujo texto unívoco em absoluto atribui competência normativa para a proibição de produtos ou insumos em caráter geral e primário. Improcedência também do pedido alternativo de interpretação conforme a Constituição do art. $7 .^{\circ}$, III, da Lei n. ${ }^{\circ}$ 9.782/1999, que confere à ANVISA competência normativa condicionada à observância da legislação vigente". (BRASIL. Supremo Tribunal Federal. ADIN 4.874/DF. Relator: Min. Rosa Weber. Julgamento: 01/02/2018. Órgão Julgador: Plenário. Publicação: DJe-019 01/02/2019, grifo nosso).

16 Preocupações com uma excessiva expansão da atuação de Agências Reguladoras não são inéditas na Academia norte-americana. Nesse sentido, v.: MANNING, 1996. 
Em relação ao segundo dilema, o formalismo jurídico teria o condão de servir como uma espécie de freio a uma possível atuação exorbitante da Agência. Novamente, o respeito ao conteúdo da norma em detrimento de outras razões serve para restringir a margem de atuação, desta vez não do juiz, mas da própria Agência, que estaria limitada por uma interpretação "formalista" dos termos empregados pelo mandato legislativo.

Observe-se que o formalismo jurídico, em ambos os casos, está relacionado a uma preocupação com alocação dos poderes e rule of law. Tanto o Judiciário controlador quanto a Agência teriam uma pretensa atuação em húbris preclusa por força do conteúdo de prescrições normativas, derivadas de atores políticos com lastro democrático. $\mathrm{O}$ formalismo prestigiaria, assim, também a democracia. ${ }^{17}$

Ambos os dilemas dizem respeito à alocação de poderes e podem comprometer a Separação dos Poderes, e o formalismo jurídico se mostra alternativa apta a salvaguardá-los.

A grande virtude, talvez, do formalismo jurídico é a sua capacidade de restringir escolhas. Essa restrição de escolhas torna o jogo jurídico menos imprevisível para os atores envolvidos, no caso da Regulação, torna a vida dos regulados mais fácil, pois saberão de antemão sob a tutela de quem estarão sujeitos.

Se o formalismo é compreendido como uma inclinação à prescrição normativa, e não a questões como as finalidades almejadas pela norma, o sentido do texto deve fornecer segurança suficiente para que todos os atores envolvidos saibam sua posição no jogo de alocação de poderes. O mandato legislativo deve ter normas cujo sentido possa ser apreciado pelos destinatários.

A preocupação com o sentido dos termos traz, contudo, alguma perplexidade em relação ao formalismo jurídico. Se o formalismo é intuitivamente relacionado ao rule of law em detrimento ao governo dos homens, Matzcak apresenta uma crítica interessante, que merece ser registrada.

Para o autor, o formalismo jurídico não seria compatível com o rule of law e não ofereceria a tão alardeada previsibilidade, pois seria fundado em uma teoria linguística denominada internalismo semântico. Diferentemente do que chama externalismo semântico, onde se investiga o sentido de determinada linguagem através de sua evolução e história dentro de determinada comunidade, o internalismo semântico determina que o sentido de

17 Cass Sunstein explorou a ideia de formalismo democrático enquanto defendida por Scalia. V.: SUNSTEIN, 1997. 
determinada linguagem é encontrado unicamente através da satisfação de critérios preestabelecidos (MATCZAK, 2018, p. 67).

O formalismo jurídico vendável à Teoria da Regulação deve estar atento, portanto, à questão do uso da linguagem. Caso pautado em uma visão linguística que não leve em conta o uso habitual dos termos, o formalismo jurídico não servirá aos fins a que se preza, especialmente no tocante à previsibilidade e à alocação adequada de poder.

A sugestão de uma abordagem formalista em relação às normas de delegação de competência às agências reguladoras carece, portanto, de uma adequada opção linguística, sob pena de tornar o formalismo ineficaz. A busca acerca do tipo de teoria semântica a ser utilizado foge, contudo, do escopo deste artigo.

\section{Conclusões}

O formalismo jurídico é uma espécie de cadáver ressurrecto da Academia do Direito. Se muitos proclamam a sua morte, outros tantos o tornam redivivo.

A Regulação, por sua vez, pode ser vista como uma espécie de Direito Público da modernidade, permeável a outros setores do conhecimento e cuidadoso com consequências práticas da intervenção estatal.

Entre o vetusto e o moderno poderia haver conciliação?

$\mathrm{O}$ artigo procurou relacionar o formalismo com elementos da Teoria da Regulação, demonstrando que há uma correlação entre ambos, e que o formalismo é defensável enquanto teoria interpretativa dos mandatos legislativos que conferem poderes às Agências Reguladoras.

Para tal, buscou, primeiramente, expor os rótulos associados ao formalismo jurídico, tentando apresentar uma versão mais caridosa a essa teoria. Após, apresentou elementos da Teoria da Regulação, especialmente em relação à Regulação por Agências, para demonstrar a existência de um nicho de aplicação do formalismo jurídico especificamente sobre mandatos legislativos que confiram poderes às Agências.

A adoção do formalismo evitaria dois extremos: um excesso de controle sobre as decisões das Agências, fomentando uma deferência ao Regulador, e um freio a possíveis expansionismos das Agências. 
Se o mundo jurídico é aquele onde a Realidade tem de ser chamada Princípio (MOREIRA NETO, 2014), seguir o texto de uma norma é um verdadeiro ato revolucionário.

\section{Referências}

ALEXANDER, Larry. Law and Formalism. University of San Diego School of Law Legal Studies Research Paper Series. San Diego Legal Studies Paper, n. 07-18, 2005.

ARGUELHES, Diego Werneck; LEAL, Fernando. Pragmatismo como [meta]teoria da decisão judicial: caracterização, estratégias e implicações. In: SARMENTO, Daniel; CRUZ, Álvaro Ricardo de Souza (Orgs.). Filosofia e teoria constitucional contemporânea. Rio de Janeiro: Lumen Juris, 2009. p. 171-211.

BALDWIN, Robert; CAVE, Martin; LODGE, Martin. Understanding Regulation: Theory, Strategy, and Practice. 2. ed. Oxford: Oxford University Press, 2012.

BINENBOJM, Gustavo. Poder de polícia, ordenação e regulação. Belo Horizonte: Fórum, 2016.

BRASIL. Decreto-lei n. ${ }^{\circ}$ 4.657, de 4 de setembro de 1942. Lei de Introdução às normas do Direito Brasileiro. Disponível em: <http://www.planalto.gov.br/ccivil_03/decretolei/del4657compilado.htm>. Acesso em: 27 dez. 2020.

BRASIL. Lei n. ${ }^{0} 13.848$, de 25 de junho de 2019. Dispõe sobre a gestão, a organização, o processo decisório e o controle social das agências reguladoras, altera a Lei n. ${ }^{\circ}$ 9.427, de 26 de dezembro de 1996, a Lei . $^{\circ}$ 9.472, de 16 de julho de 1997, a Lei n. ${ }^{\circ} 9.478$, de 6 de agosto de 1997, a Lei n. ${ }^{\circ}$ 9.782, de 26 de janeiro de 1999, a Lei n. ${ }^{\circ} 9.961$, de 28 de janeiro de 2000, a Lei n. ${ }^{\circ} 9.984$, de 17 de julho de 2000, a Lei n. ${ }^{\circ} 9.986$, de 18 de julho de 2000, a Lei n. ${ }^{\circ}$ 10.233, de 5 de junho de 2001, a Medida Provisória n. ${ }^{\circ}$ 2.228-1, de 6 de setembro de 2001, a Lei n. ${ }^{\circ} 11.182$, de 27 de setembro de 2005, e a Lei n. ${ }^{\circ} 10.180$, de 6 de fevereiro de 2001. Disponível em: <http://www.planalto.gov.br/ccivil_03/_ato2019-2022/2019/lei/L13848.htm>. Acesso em: 27 dez. 2020.

BRASIL. Supremo Tribunal Federal. ADIN 4.874/DF. Relator: Min. Rosa Weber. Julgamento: 01/02/2018. Órgão Julgador: Plenário. Publicação: DJe-019 01/02/2019.

BRASIL. Supremo Tribunal Federal. HC 101132 ED. Relator: Min. Luiz Fux. Julgamento: 24/04/2012. Órgão Julgador: 1. ${ }^{a}$ Turma. Publicação: ACÓRDÃO ELETRÔNICO DJe-099 DIVULG 21/05/2012 PUBLIC 22/05/2012.

COLEMAN, Jules. The Architecture of Jurisprudence. The Yale Law Journal, v. 121, n. 1, 2011. Disponível em: <https://www.yalelaw journal.org/pdf/1009_3fnvkd8i.pdf>. Acesso em: 30 out. 2020.

ESTADOS UNIDOS. Constituição do Estado de Massaschusetts de 1780. Disponível em: <https://malegislature.gov/laws/constitution>. Acesso em: 28 dez. 2020. 
ESTADOS UNIDOS. Suprema Corte dos Estados Unidos da América: 467 U.S. 837, Chevron U.S.A inc. v. Natural Resources Defense Council, inc. Data de julgamento: 25/06/1984. Disponível em: 〈https://www.law.cornell.edu/supremecourt/text/467/837>. Acesso em: 27 dez. 2020.

GUERRA, Sérgio. Aperfeiçoando a regulação brasileira por agências: quais lições podem ser extraídas do sesquicentenário modelo norteamericano? In: Teoria do estado regulador. Curitiba: Juruá, 2015. p. 13-106.

LEAL, Fernando. O formalista expiatório: leituras impuras de Kelsen no Brasil. Revista Direito GV, São Paulo, v. 10, n. 1, p. 245-268, jan./jun. 2014.

LEAL, Fernando. "A Constituição diz o que eu digo que ela diz": formalismo inconsciente e textualismo oscilante no Direito Constitucional brasileiro. Direitos Fundamentais \& Justiça, Belo Horizonte, v. 12, n. 39, p. 99-143, jul./dez. 2018.

LEAL, Fernando. Análise de impacto regulatório e proporcionalidade: semelhanças estruturais, mesmos problemas reais? Revista Brasileira de Políticas Públicas, v. 9, n. 3, p. 313-349, dez. 2019.

LEITER, Brian. Legal Formalism and Legal Realism: what is the issue? Legal Theory, v. 16, n. 2, p. 111-133, jun. 2010.

MANNING, John F. Constitutional structure and judicial deference to agency interpretations of agency rules. Columbia Law Review, v. 96, n. 3, p. 612-696, abr. 1996.

MATCZAK, Marcin. Why Judicial Formalism is Incompatible with the Ruleof Law. Canadian Journal of Law and Jurisprudence, v. 31, n. 1, p. 61-85, fev. 2018. Disponível em: <https://www.cambridge.org/core/journals/canadian-journal-of-law-andjurisprudence/article/why-judicial-formalism-is-incompatible-with-the-rule-oflaw/F1192A032424D36137AD7634F6BAE690>. Acesso em: 26 dez. 2020.

MOREIRA NETO, Diogo de Figueiredo. Curso de direito administrativo. 14. ed. Rio de Janeiro: GEN, 2014.

ORBACH, Barak. What is Regulation? Yale Journal on Regulation Online, v. 30, n. 1, p. 110, 2012. Disponível em: <https://papers.ssrn.com/sol3/papers.cfm?abstract_id=2143385>. Acesso em: 27 dez. 2020.

POSNER, Richard A. Legal Formalism, Legal Realism and the interpretation of statutes and the Constitution. Case Western Reserve Law Review, v. 37, n. 2, p. 179-217, 1986.

REDISH, Martin H.; CISAR, Elisabeth J."If angels were to govern": the need for Pragmatic Formalism in Separation of Powers Theory. Duke Law Review, v. 41, n. 3, p. 449-506, dez. 1991. Disponível em: “"If Angels Were to Govern": The Need for Pragmatic Formalism in Separation of Powers Theory on JSTOR>. Acesso: 27 dez. 2020.

SCHAUER, Frederick. Formalism. The Yale Law Journal, v. 97, n. 4, p. 509-548, mar. 1988. 
SELZNICK, Philip. Focusing Organizational Research on Regulation. In: NOLL, Roger G. (Ed.). Regulatory Policy and the Social Sciences. Berkeley: University of California Press, 1985. p. 1-3.

STOKES, Michael. Formalism, Realism, and the Concept of Law. Law and Philosophy, v. 13, n. 2, p. 115-159, mar. 1994.

SUNDFELD, Carlos Ari. Direito administrativo ordenador. 3. ${ }^{a}$ tiragem. São Paulo: Malheiros, 2003.

SUNSTEIN, Cass. Justice Scalia's Democratic Formalism. The Yale Law Journal, v. 107, n. 2, p. 528-567, nov. 1997.

SUNSTEIN, Cass R. Must formalism Be Defended Empirically?. The University of Chicago Law Review. John M. Olin Program in Law and Economics Working Paper, n. 70, 1999. Disponível em:

<https://chicagounbound.uchicago.edu/cgi/viewcontent.cgi?article=1329\&context=law_and_e conomics >. Acesso em: 23 dez. 2020. 